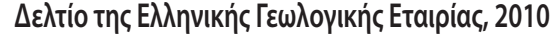

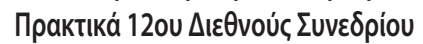

Пátpa, Máıǫ 2010
Bulletin of the Geological Society of Greece, 2010

Proceedings of the 12 th International Congress

Patras, May, 2010

\title{
GEOPHYSICAL RESEARCH FOR GEOLOGICAL STRUCTURE DETERMINATION IN THE REGION OF SOUTH MESOGHEIA (ATTICA)
}

\begin{abstract}
Alexopoulos J.D. ${ }^{1}$ and Dilalos S. ${ }^{1}$
${ }^{1}$ National and Kapodistrian University of Athens, Faculty of Geology and Geoenvironment, Department of Geophysics - Geothermics, 157-84, Panepistimiopolis, Athens, Greece, jalexopoulos@geol.uoa.gr, sdilalos@geol.uoa.gr
\end{abstract}

\begin{abstract}
During the last years the broader area of Koropi (Mesogheia-Greece), has faced rapidly increasing problems concerning irrigation and watering of the town, due to the brackish water in the water supply boreholes. Our main target is to determinate the subsurface geological structure of the study area, located NE of the Koropi city, where alterations of schists and carbonates, from three different post-alpine units, mainly appear and relate it with the groundwater flow paths. The dominant geological outcrops of the area are the Athenian Schist (Laurion-Attica Unit), the dolomitic marbles (Vari-Kirou Pira Unit) and the Lower Marble (Hymittos Unit). A geophysical research was carried out in the area mainly based on the geoelectrical methodology, including by executing fifteen Vertical Electrical Soundings and one Electrical Resistivity Tomography. The interpretation results of the geophysical data have been evaluated and combined with "in-situ" resistivity measurements and calibrated with cores coming from drilled boreholes revealing the area. Through this combining process important elements of the local geological subsurface structure have been determined, as the formation of the dolomitic marbles (massive or karstified) was found tilting southwards beneath the Athenian Schist. From a hydrogeological point of view, this alone adds a significant parameter to the subsurface geological structure which is highly related to the groundwater flow that is responsible for many problems and could be used for solving many others.
\end{abstract}

Key words: Electrical soundings, Resistivity tomography, Koropi.

\section{Introduction}

During the last few years, in the study area the economic development is quite increased, with many industries and agriculture, with the second covering a major part of the Mesogheia area. The industrial zone is located north-westwards of the Koropi town. The geological structure of the area is quite complicated, consisting of 3 different lithological units. Due to some existing hydrogeological problems of the area, including the appearance of brackish water in almost every borehole in the area, a geophysical investigation has been carried out, in order to determine in detail the geological structure of the area. The study area is located SSE of Koropi city, around the road leading to Markopoulo and east of the road to Vari.

The geological formations outcropping in the area, are schists from three different units generally, 
impermeable and conductive formations, but also two types of marbles, either massive or locally karstified, comprising a complicated hydrogeological regime. Additional data come from several boreholes that are mainly used for irrigation and watering. For many of these boreholes, core data were kindly provided by Dr. Spyridon Lekkas, Professor of Hydrogeology, to the authors.

\section{Geological setting}

A typical succession from the shallowest to the deepest formations at the region of Mesogheia contains the following (Fig. 1): The Quaternary deposits, the Neogene formations, the allochthonous unit members of Cretacious limestones and the underlying Athenian Schist, the autochthonous unit members of superior marble and the underlying Kaissariani Schist, the Lower Marble, the Pirnaris dolomites and finally the Vari Schist.

A rough description of the post-alpine deposits follows:

- The Pleistocene deposits cover the major part of the study area. They mostly consist of non-homogeneous inarticulate conglomerates and red clays. Their thickness varies from some meters to hundreds of metres, eastwards and north-westwards. They are characterized by the presence of a calcareous crust, caused by the climatic influence.

- The Neogene deposits are comprised by marls, sandstones, calcareous marls and conglomerates, with pebbles coming from marbles, schisteous marbles, ultrabasic and pyrites.

The alpine formations can be categorized in the following three tectono-stratigraphic units.

- The Laurion-Attica Unit: Consisted of the Athenian Schist, whose thickness reaches up to 120 meters thick, according to drilling data. This schist consists mostly of phyllites, argillaceous schists, green schists with low content of metamorphic sandstones and quartz with high content of basic and ultrabasic formations.

- The Hymittos Unit: is represented by the Kaissariani Schist and the Lower Marble (Jurassic). This schist contains muscovites, calcareous schists with chlorites, limestones, serpentinites and marbles intercalations. The Lower Marble outcrops mainly at the southern parts of the study area, having a significant thickness and a variety of colours, as white, bluish or reddish.

- The Unit of Vari-Kirou Pira: It is the basement unit of Attica, including three different formations in the study area, which are the dolomites of Pirnaris, the dolomitic marbles (sipolines and impure marbles) and the Vari Schist. The dolomites of Pirnaris, are located eastwards of the study area with maximum thickness equal to 250 meters. They are crustal thin-bedded with various colours, from white to reddish, covering the Vari Schist where they interpose. The dolomitic marbles appear southwards of the area and are composed of a continuous alternation of crystalline marbles and dolomitic marbles, including levels of schists with muscovites, chlorites and limestones (Lekkas and Lozios, 2000).

\section{Resistivity Survey}

The resistivity survey was applied in the area, due to the existing geological formations and their different impact on resistivity. The geoelectrical data include six (6) "in-situ" resistivity measurements next to boreholes and surface outcrops of the geological formations, fifteen (15) ver- 


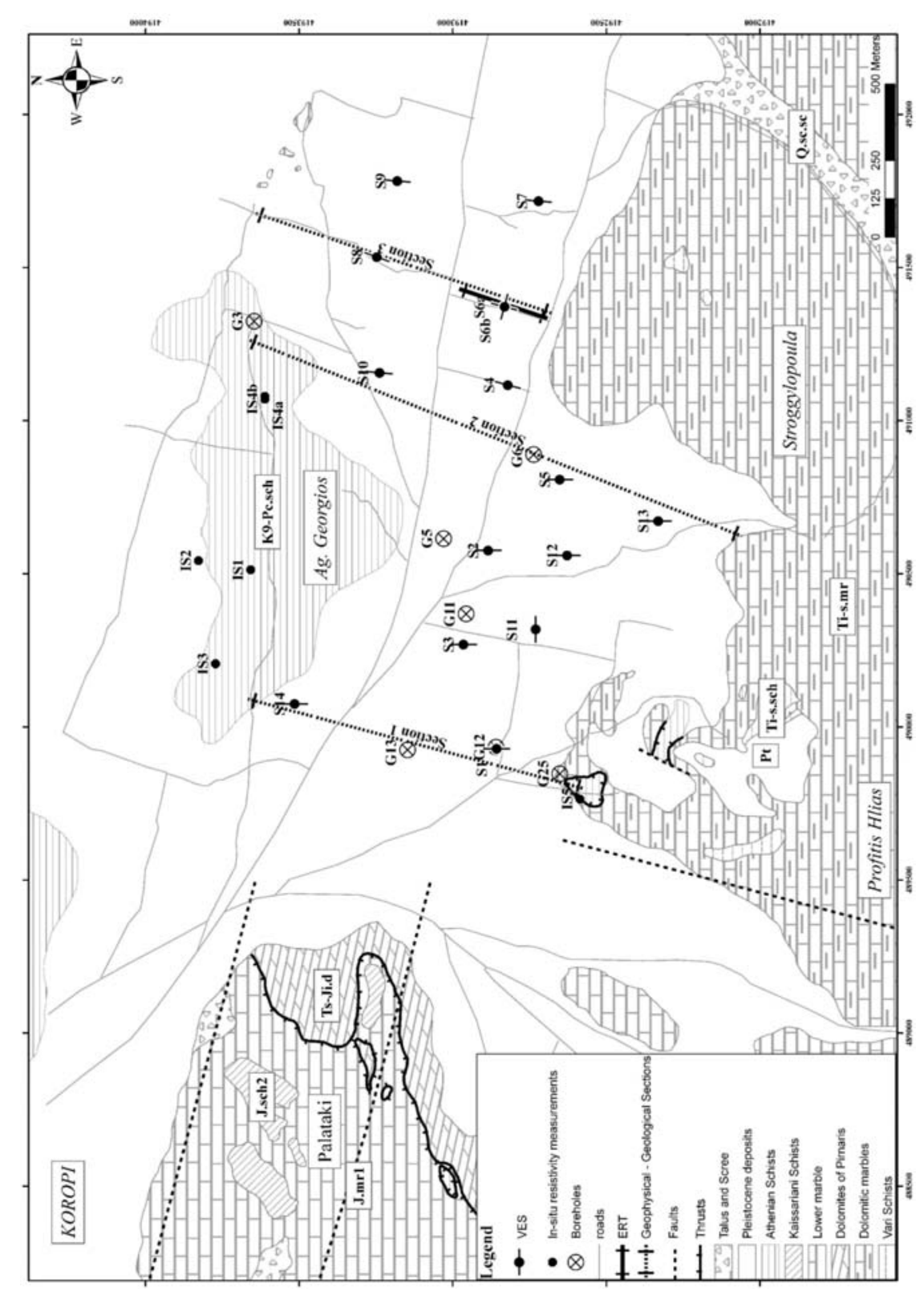

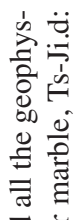

छี

ฮำ

寻

छ

$\exists \Xi$

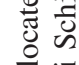

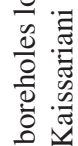

巳

㺼

율

ฮี

龸导

Ð

पै

के

은

สิ

证 吾

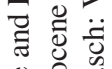

疍

空远

월

छ

.

응

品 \&

氖苛

$\because \ddot{g}$

छ

룽

导苞

플

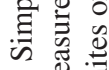

$\ddot{\nabla}$.

ํํำ 
Table 1.

\begin{tabular}{|c|c|}
\hline Geological Formation & Resistivity $(\mathbf{O h m} . \mathbf{m})$ \\
\hline Pleistocene deposits & $17-25$ \\
\hline Athenian Schist & $43-200$ \\
\hline Dolomitic marbles & $350-900$ \\
\hline Vari Schist & $150-200$ \\
\hline
\end{tabular}

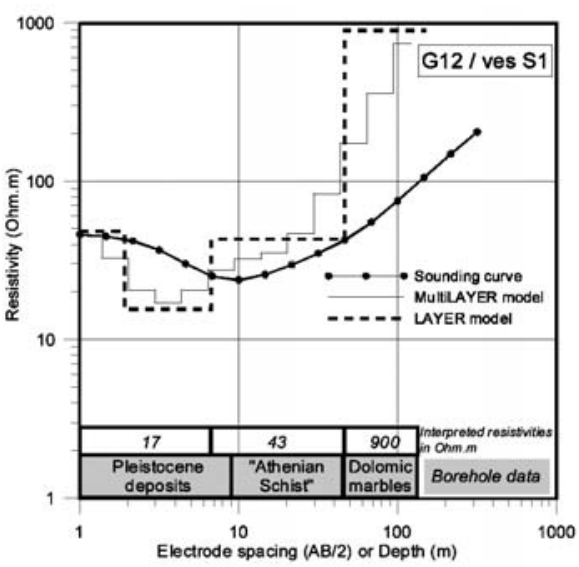

(a)

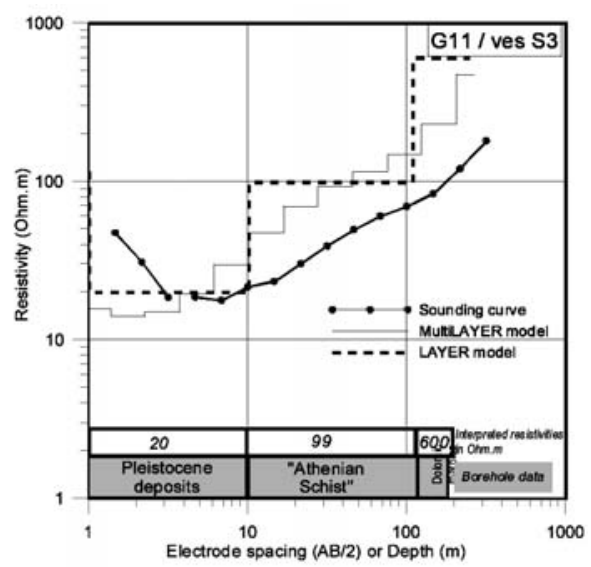

(b)

Fig. 2: Interpretation results of VES S1 (a) and S3 (b) integrated with the corresponding drilling data of G12 and G11.

tical electrical soundings (VES) for the investigation of the geological structure and a 200-m electrical resistivity tomography (ERT), for a more detailed evaluation. All these data were collected in the flat area between the Ag.Georgios and Stroggylopoula hills.

\section{1 "In-situ" resistivity measurements - Calibration}

In order to calibrate and better evaluate the geoelectrical results, four (4) "in-situ" resistivity measurements were carried out, above outcrops of the existing geological formations and mostly above Athenian schist's outcrops, applying the Schlumberger array, with maximum AB length equal to 215 meters. Furthermore, some soundings (S1, S3) were carried out next to existing boreholes (waterless during the resistivity measurements period), for which the drilling data were provided by Prof. Lekkas Sp. This ensured the best possible calibration and interpretation of processing results (Fig. 2) and contributed to an accurate definition of the corresponding resistivity limits of each geological formation (Table 1).

Specifically, the interpretation results of the S1 sounding, carried out next to borehole G12 (Fig. 2a), revealed for the Pleistocene deposits, resistivity values of approximately 17 Ohm.m, for the Athenian Schist values of 43 Ohm.m and for the massive dolomitic marbles 900 Ohm.m. Furthermore, the interpretation of S3, calibrated with the G11 borehole data (Fig. 2b), revealed 20 Ohm.m resistivity for the Pleistocene deposits, 99 Ohm.m for the Athenian Schist and approximately $600 \mathrm{Ohm} . \mathrm{m}$ indicating the dolomitic marbles. 


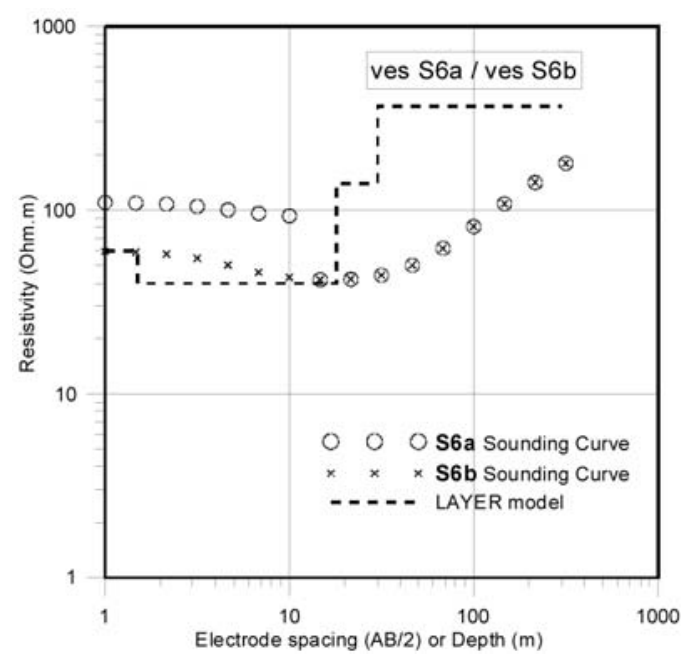

Fig. 3: Field data of VES S6a and S6b ("crossdirection") and processing results, based on VES S6b.

\subsection{Vertical Electrical Soundings}

Fifteen (15) resistivity soundings (VES) were conducted, using the Schlumberger array. Maximum current electrode spacing $(\mathrm{AB})$ reached up to 928 meters with a quite good distribution around the study area, considering the district construction (traffic streets, residences, fences, etc) and vegetation. An ABEM Terrameter SAS300C and Booster 2000 were used for the field measurements. The geophysical data were processed by applying the automatic method of Zohdy and Bisdorf (Zohdy, 1989), composing a "multilayer" model. Beyond this, the commercial software package IX1D (v3) of Interpex, was used in order to come up with the "layered" model.

At the location of S6 (Fig. 1), two separate sounding were carried out, first the S6a $\left(\mathrm{N} 15^{\circ}\right.$ electrodes expansion) and then the $\mathrm{S} 6 \mathrm{~b}$ (N105 electrodes expansion), with fixed centre, but with perpendicular direction. These "cross-direction" soundings carried out due to an unexpected parallel shift of S6a curve's part (Fig. 3). Based on Zohdy et al. (1974), this shift usually derives from a subsurface vertical and thin geological formation or fault crossing perpendicular the electrode spacing expansion. One way to qualitatively check the existence of this possible geological anomaly, was the sounding S6b (Fig. 3), with the perpendicular electrodes expansion. Normally, at the curve of S6b there will not be any parallel shift, considering that its direction would now be parallel to any possible existing geological anomaly that caused the curve shift of S6a.

\subsection{Electrical Resistivity Tomography}

Due to the problem derived from the S6a curve's shift, combined with the curve of the perpendicular S6b sounding, the necessity of a more detailed geophysical technique was essential. The best solution for this unusual problem was the implementation of the Electrical Resistivity Tomography method, by which we obtain detailed data for the lateral and vertical resistivity distribution.

Consequently, a 200-m electrical resistivity tomography profile was carried out, using the ABEM Terrameter SAS300C along with the ABEM electrode selector ES-464. The system had 60 electrodes, providing the automatic measurements of apparent resistivity, using the Wenner array with an electrode spacing of $2.5 \mathrm{~m}$. The centre of the ERT profile, at $100 \mathrm{~m}$, is identical with 

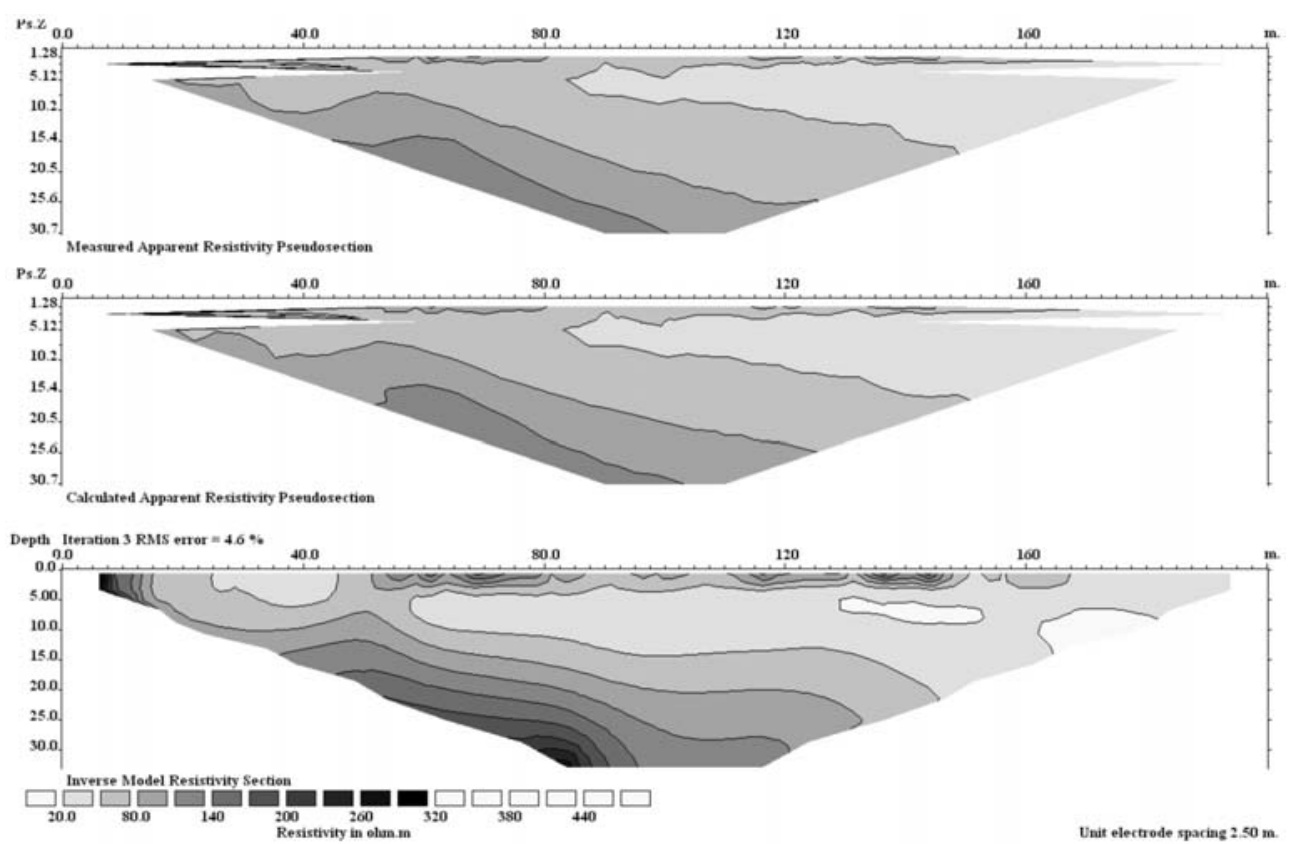

Fig. 4: Processing results of the ERT method. Top: Measured apparent resistivity pseudosection, Middle: Calculated apparent resistivity pseudosection, Bottom: Inverse model resistivity section.

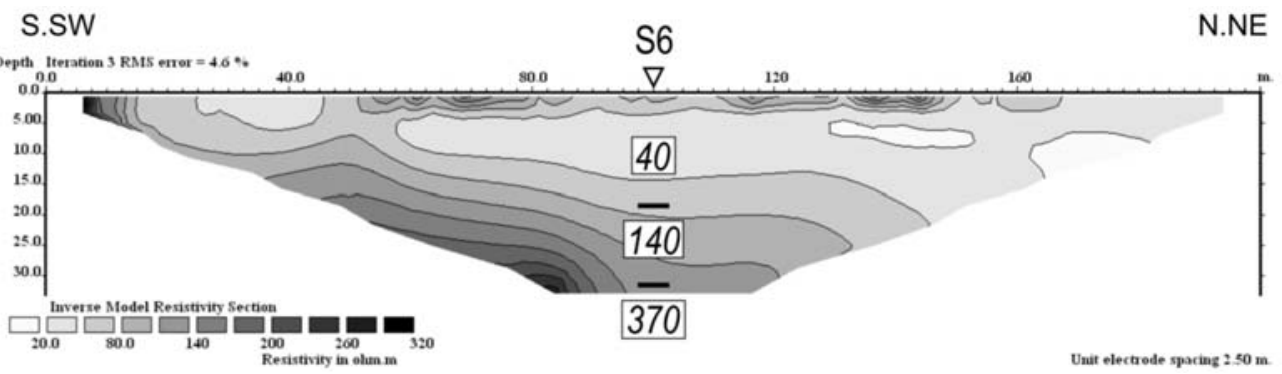

Fig. 5: Combined 2D resistivity tomography inversion model and 1D results of VES S6b.

the centre of the "cross-direction" soundings S6a and S6b (Fig. 5), in order to have the best evaluation of the processing results. The direction of the ERT profile is the same with the one of S6a $\left(\mathrm{N} 105^{\circ}\right)$.

The electrical resistivity tomography measurements (totally 190 points), were processed with the RES2DINV software of GeoTomo (Fig. 4).

The inverse model resistivity section, derived from this processing, indicated a tilted geoelectrical structure, which by no means can be connected with a vertical geological formation that was supposed to cause the curve shift of S6a. As it seems, this tilt was sufficient enough to shift the curve of S6a. 


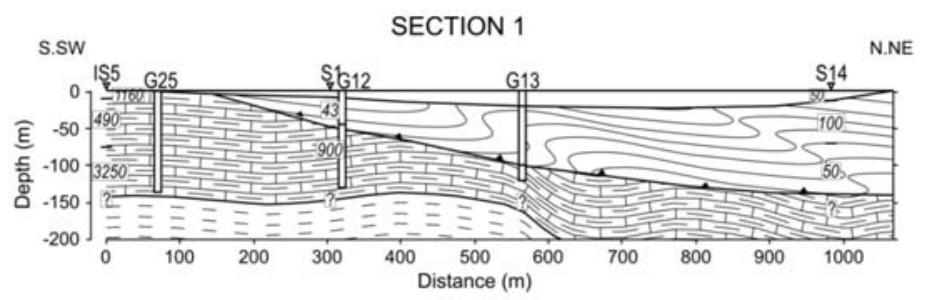

SECTION 2

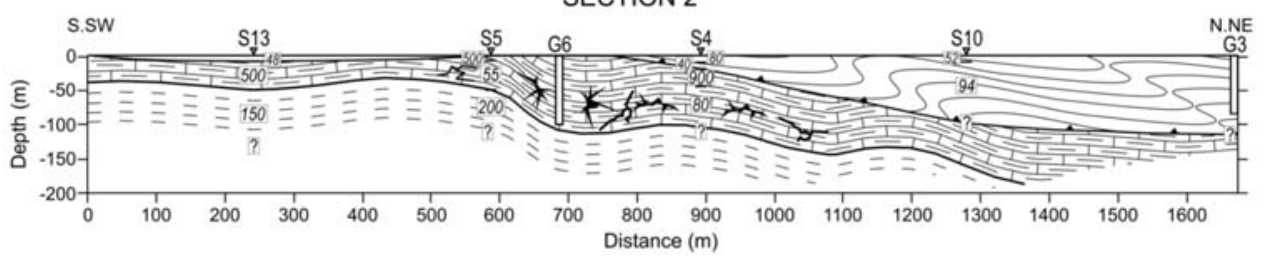

SECTION 3

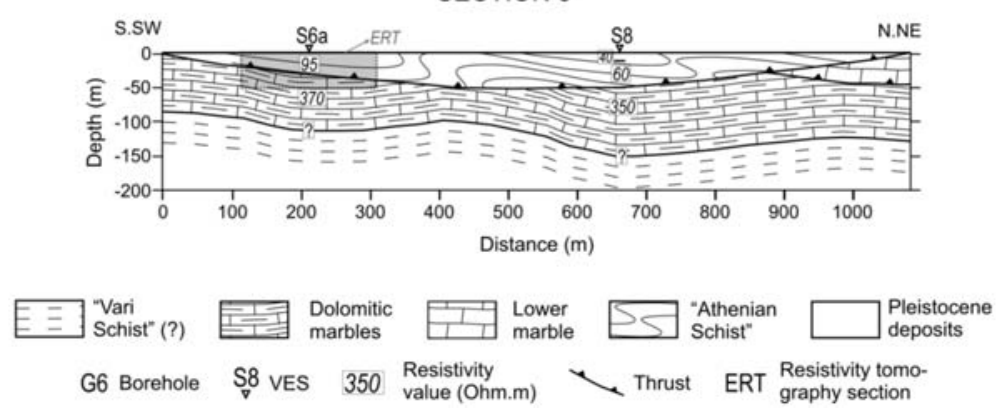

Fig. 6: Integrated geological and geophysical sections (the locations of these sections are illustrated in the geological map of Fig. 1).

At Fig. 5, the 2D inversion model of the resistivity tomography is illustrated along with the 1D layer results of the sounding S6b, revealing a first layer of $40 \mathrm{Ohm} . \mathrm{m}$ resistivity and approximately $18 \mathrm{~m}$ thickness. Underlying this, a more resistive formation seems to be present, with resistivity around $140 \mathrm{Ohm} . \mathrm{m}$ and $14 \mathrm{~m}$ thickness, tilting to NNE. The deepest investigated geoelectrical layer is even more resistant, up to 370 Ohm.m.

\subsection{Integrating geophysical and geological results}

Based on the interpretations of all the geophysical data of the study area, including all the soundings and the resistivity tomography, combined with the surface geological data and drilling stratigraphy columns, three (3) geoelectrical-geological sections were constructed (Fig. 6), in a NNE-SSW direction, beginning from Stroggylopoula hill and ending at Ag. Georgios hill (Fig. 1), in an effort to illustrate the subsurface geological structure of the small valley.

In these sections, five (5) different geological formations have been investigated, one of which is the geolectrical basement of the Vari Schist, an impermeable formation contributing significantly at the hydrogeological conditions of the area. The presence of the Pleictocene deposits, covering almost all the area, is obvious. This layer seems to cover the thrust of the folded Athen- 


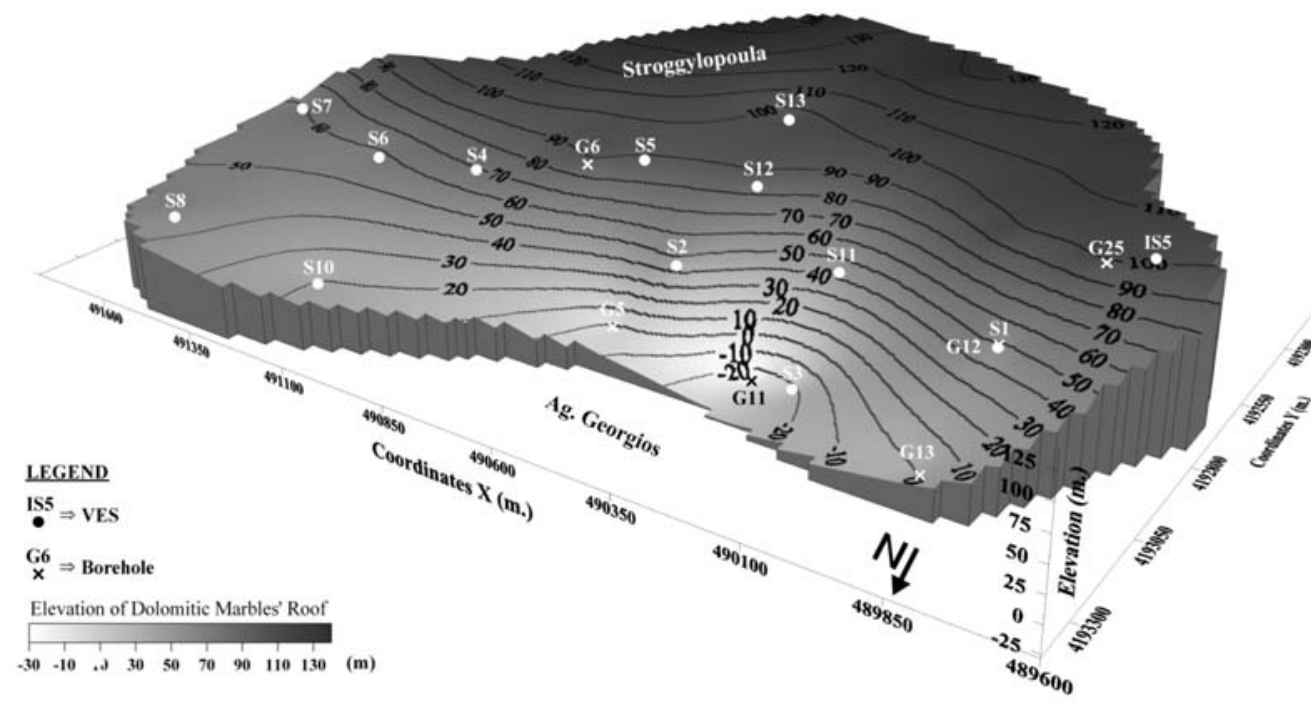

Fig. 7: 3-D representation of the dolomitic marbles' roof elevation.

ian Schist over the locally karstified dolomitic marbles, appearing on the surface of Stroggylopoula hill. In this karstified formation the brackish aquifer (Section 2, S4-S5 area, 55-80 Ohm.m) of the area is probably located, from which the boreholes pump the water out.

In Sections 1 and 2, the Athenian Schist appears with a tilt to NNE, exceeding until a depth of almost 150 meters near the soundings S14 and S10. On the contrary, in section 3, located at the boundaries of the valley, between the two hills, the Athenian Schist is illustrated with a maximum depth of approximately 50 meters and overlying the Lower marble at the NNE edge of the section.

In Section 3 (Fig. 6), the grey box corresponds to the Resistivity Tomography (Fig. 5). The two techniques seems to fit quite well, both illustrating the tilt of the first geoelectrical-geological to NNE.

\section{Conclusions-Results}

After the evaluation of the geophysical measurements combined with the geological and borehole data, the formation of the dolomitic marbles seems to have been investigated at all the soundings. Based on this, a 3-D representation has been produced (Fig. 7), illustrating the elevation of the roof of the dolomitic marbles formation (massive or karstified). The tilt of the dolomitic marbles to the North is definite, with the Athenian Schist overlying with an increasing thickness to the North. The maximum depth for the roof of the dolomitic marbles is approximately 110 meters (absolute elevation is $-27 \mathrm{~m}$., when surface elevation is $+137 \mathrm{~m}$.), located northwards of the area (Fig. 7) and based on combined geophysical and drilling data. The thickness of the overlying Athenian Schist at this point is approximately 100 meters.

The impermeable formation of Vari Schist has been investigated as the geoelectrical basement (150-200 Ohm.m) only in few soundings, such as S2, S3, S4, S11, S12 and S13, all located in the central part of our study area. The AB extent of the other soundings wasn't possibly enough 
to investigate the formation of Vari Schist, located in greater depths, likely due to the tilt of the overlying dolomitic marbles to the North.

Regarding specifically the geophysical processing results, the model evaluation of the sounding S06a fits with the inverse model of the electrical resistivity tomography (Fig. 4), raising no doubts for the processing results. Moreover, the evaluation of the geophysical data with the valuable drilling data, leads to a better determination of the subsurface geological structure of the area, where no faults have been investigated, as the formations are quite folded.

\section{Acknowledgments}

The authors would like to thank Dr. Spyridon Lekkas, Professor of hydrogeology (NKUA, Fac. of Geology and Geoenvironment), for the valuable drilling data that he offered us orally and for his help during the geological evaluation and understanding of the geology. The authors would also like to thank Gkoumas G., Ihyanne B., Antonatos G., Gkouvailas A, Stavrou A. and Papanikolaou $\mathrm{N}$. for their contribution during the field work campaign.

The project is founded by the NKUA Special Account for Research Grants (contract No. 70/4/7620).

\section{References}

Ihyane, B., 2007. Hydrogeological study of the grainy and karstic aquifers of the region between Koropi-Markopoulo and airport. Master thesis, National Kapodistrian University of Athens, Athens, $148 \mathrm{p}$.

Ihyane, B., Lekkas, S., 2008. Degradation anthropogene de la nappe karstique de la region de Mesogheia (Attique, Grece). Proceedings of $8^{\text {th }}$ International hydrogeological congress of Greece, Athens, Vol.2, 829-838.

Lekkas, S. and Lozios, S., 2000. Tectonic structure of Mt. Hmyittos. Ann. Geol. Pays Hellen., Vol.38, 47-62.

Loke, M.H., 1999. Electrical imaging surveys for environmental and engineering studies - A practical guide to $2 D$ and $3 D$ surveys, Malaysia, $57 \mathrm{p}$.

Zohdy, A.A.R., 1989. A new method for the automatic interpretation of Schlumberger and Wenner sounding curves, Geophysics, Vol. 54-2, 245-253.

Zohdy, A.A.R, Eaton, G.P. and Mabey, D.R., 1974. Application of surface geophysics to groundwater investigations. Techniques of water-resources investigations, U.S. Geological Survey, Book 2, Chapter D1, $116 \mathrm{p}$. 